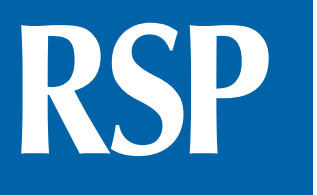

http://www.rsp.fsp.usp.br/
Revista de Saúde Pública

\title{
International Classification of Functioning in professional rehabilitation: instruments for assessing work disability
}

\author{
Juliana Scholtão Luna' ID, Gina Torres Rego Monteiro" iD, Rosalina Jorge Koifman" iD, \\ Anke Bergmann"I iD \\ I Universidade Federal do Acre. Diretoria de Saúde e Qualidade de Vida do Servidor Federal. Rio Branco, AC, Brasil \\ " Fundação Oswaldo Cruz. Escola Nacional de Saúde Pública. Departamento de Epidemiologia e Métodos \\ Quantitativos em Saúde. Rio de Janeiro, RJ, Brasil \\ III Instituto Nacional de Câncer (INCA). Programa de Epidemiologia Clínica. Rio de Janeiro, RJ, Brasil
}

\section{Correspondence:}

Juliana Scholtão Luna

Setor de Fisioterapia. Universidade Federal do Acre

Rodovia BR 364, Km 04

69920-900 Rio Branco, AC, Brasil

E-mail: juliana.s.luna@gmail.com

Received: Jan 20, 2019

Approved: Aug 05, 2019

How to cite: Luna JS, Monteiro

GTR, Koifman RJ, Bergmann

A. International Classification of Functioning in professional rehabilitation: instruments for assessing work disability. Rev Saude Publica. 2020;54:45.

Copyright: This is an open-access article distributed under the terms of the Creative Commons Attribution License, which permits unrestricted use, distribution, and reproduction in any medium, provided that the original author and source are credited.

\section{ABSTRACT}

OBJECTIVE: To review the main instruments of functional assessment and health status cited in the literature to evaluate Brazilian workers and verify the compatibility of their items with the core set for professional rehabilitation.

METHODS: A review of the literature was conducted in the main databases in search of articles that used assessment instruments in populations of workers between 2007 and 2017. Subsequently, the contents of the identified instruments were retrieved, and two evaluators analyzed their items to verify the compatibility with the categories of the core set of the International Classification of Functioning for professional rehabilitation. Cohen's kappa coefficient was used to evaluate the agreement between the evaluators.

RESULTS: Five specific and eight generic instruments were selected to evaluate the functioning of workers. The analysis of the items of the total instruments allowed the definition of 58 categories (64.5\%) of the core set with minimal overlap: 13 (76.5\%) of the body functions component, $29(72.5 \%)$ of the activities and participation component and 16 (49\%) environmental factors.

CONCLUSIONS: The association of several instruments requires time and makes it difficult to use the classification. The development of instruments with direct association with its categories is essential to operationalize it.

DESCRIPTORS: Disability Assessment. Occupational Health. International Classification of Functioning, Disability and Health. Systematic Review. 


\section{INTRODUCTION}

The use of classification instruments in the area of occupational health facilitates the understanding of different work-related injuries and disabilities ${ }^{1,2}$, since its consequences can vary. The standardization of language on the health status of workers optimizes the relationships between the various areas that make up the intervention team, enabling integrated and effective actions to return to work ${ }^{1-3}$.

The World Health Organization (WHO) proposes two classifications to record information on the health conditions and states of populations. The first is the International Statistical Classification of Diseases and Related Health Problems (ICD), which codifies health conditions in terms of signs and symptoms. The second is the International Classification of Functioning, Disability and Health (ICF), which classifies the impact of these conditions

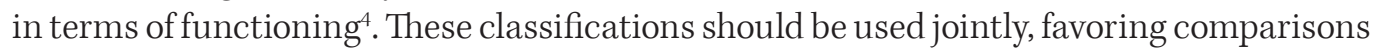
in research, data records, as well as feeding information systems and reporting statistics in public health ${ }^{5,6}$.

Professional rehabilitation (PR) is described as the main process to promote workers' health, aiming to keep the worker active or providing their return to work in cases of illness or disability ${ }^{1,7,8}$. It should be carried out under a interprofessional approach, with actions ranging from disease prevention and health care to changes in the work environment ${ }^{1,2,9}$.

In Brazil, PR is historically attributed to the Ministry of Social Security, having as its central criterion the identification of disability through expertise with subsequent granting of benefit to the worker on leave and referral to a professional guidance program that aims to promote means (training and courses) for the worker to be reinserted in the labor market ${ }^{10}$. It does not necessarily include integrated physical and/or psychological rehabilitation actions, which are the tasks of the Ministry of Health, offered by rehabilitation centers, not necessarily specialized in this area of activity ${ }^{10,11}$.

The Technical Manual of Procedures in the Area of Professional Rehabilitation, 2016, points to an advance in this area, recognizing that PR should include combined actions of care, surveillance and health care, including social reintegration and environmental analysis, with the performance of a specialized multidisciplinary team of public and intersectoral responsibility and guided by ICF throughout its preparation ${ }^{12}$. However, the disarticulation between the responsible sectors and the lack of a consistent public policy still contribute to the lack of implementation of an efficient PR program in Brazil, with many workers unable to return to their work activities ${ }^{10}$.

The ICF Research Branch is an important WHO collaborating center for studies with ICF and is a reference in PR publications. The adoption of the WHO biopsychosocial model, as well as the use of ICF in PR, are already consolidated by allowing a comprehensive view of work disability and language standardization, improving communication between health professionals, users, employers and public policy managers, favoring the expected results with $\mathrm{PR}^{13}$.

In this sense, a group of researchers from this center elaborated in 2012 the core set for $\mathrm{PR}$, to serve as a reference in the description of worker functioning ${ }^{2}$. The core set is a short list of categories of ICF, elaborated by expert consensus in a given area, as a strategy proposed by the WHO to facilitate the use of classification among professionals from the various sectors ${ }^{14}$.

The core set for PR brings together 90 categories of ICF and is applicable to any class of workers, regardless of health conditions. It is divided in 17 categories related to body functioning, 40 categories regarding activities and participation and 33 related to environmental factors (Table 1). 
Table 1. Categories of the core set of the International Classification of Functioning, Disability and Health for professional rehabilitation according to Finger et al. ${ }^{12}$

\begin{tabular}{|c|c|c|c|c|c|}
\hline \multicolumn{2}{|c|}{ Body functions (b) } & \multicolumn{2}{|c|}{ Activity and participation } & \multicolumn{2}{|c|}{ Environmental factors (e) } \\
\hline $\begin{array}{l}\text { ICF } \\
\text { category }\end{array}$ & Category description & $\begin{array}{c}\text { ICF } \\
\text { category }\end{array}$ & Category description & $\begin{array}{c}\text { ICF } \\
\text { category }\end{array}$ & Category description \\
\hline b 117 & Intellectual functions & d 155 & Skill acquisition & e 1101 & Medication \\
\hline b 126 & $\begin{array}{l}\text { Temperament and } \\
\text { personality }\end{array}$ & d 160 & Focus & e 115 & $\begin{array}{l}\text { Products for personal } \\
\text { use in daily life }\end{array}$ \\
\hline b 130 & $\begin{array}{l}\text { Energy and impulse } \\
\text { functions }\end{array}$ & d 163 & Thinking & e 120 & $\begin{array}{l}\text { Personal mobility } \\
\text { products }\end{array}$ \\
\hline b 134 & Sleep functions & d 166 & Reading & e 125 & $\begin{array}{l}\text { Products and } \\
\text { technologies for } \\
\text { communication }\end{array}$ \\
\hline b 140 & $\begin{array}{l}\text { Attention-related } \\
\text { functions }\end{array}$ & d 170 & Writing & e 130 & $\begin{array}{l}\text { Products and } \\
\text { technologies for } \\
\text { education }\end{array}$ \\
\hline b 144 & Memory functions & d 172 & Mathematical thought & e 135 & $\begin{array}{l}\text { Products and technology } \\
\text { for employment }\end{array}$ \\
\hline b 152 & Emotional functions & d 175 & Problem-solving & e 150 & $\begin{array}{c}\text { Architecture, public use } \\
\text { construction }\end{array}$ \\
\hline b 160 & Thought functions & d 177 & Decision-making & e 155 & $\begin{array}{l}\text { Architecture, private } \\
\text { use construction }\end{array}$ \\
\hline b 164 & $\begin{array}{l}\text { High-level cognitive } \\
\text { functions }\end{array}$ & d 210 & $\begin{array}{l}\text { Accomplishing a single } \\
\text { task }\end{array}$ & e 225 & Climate \\
\hline b 210 & $\begin{array}{l}\text { Vision-related } \\
\text { functions }\end{array}$ & d 220 & Perform multiple tasks & e 240 & Light \\
\hline b 230 & $\begin{array}{l}\text { Hearing-related } \\
\text { functions }\end{array}$ & d 230 & $\begin{array}{l}\text { Accomplishment of daily } \\
\text { routine }\end{array}$ & e 250 & Sound \\
\hline b 235 & Vestibular functions & d 240 & $\begin{array}{c}\text { Dealing with stress and } \\
\text { other psychological } \\
\text { demands }\end{array}$ & e 260 & Air quality \\
\hline b 280 & Feeling of pain & d 310 & $\begin{array}{l}\text { Communication and } \\
\text { reception of verbal } \\
\text { messages }\end{array}$ & e 310 & Immediate family \\
\hline b 455 & $\begin{array}{l}\text { Tolerance to physical } \\
\text { exercise }\end{array}$ & d 315 & $\begin{array}{l}\text { Communication and } \\
\text { reception of nonverbal } \\
\text { messages }\end{array}$ & e 320 & Friends \\
\hline b 730 & $\begin{array}{l}\text { Muscle strength } \\
\text { functions }\end{array}$ & d 350 & Talking & e 325 & $\begin{array}{l}\text { Acquaintances, peers, } \\
\text { colleagues, neighbors }\end{array}$ \\
\hline b 740 & $\begin{array}{l}\text { Muscular endurance } \\
\text { functions }\end{array}$ & d 360 & $\begin{array}{c}\text { Use of communication } \\
\text { devices }\end{array}$ & e 330 & Authority figures \\
\hline \multirow[t]{11}{*}{ b 810} & $\begin{array}{l}\text { Skin protection } \\
\text { functions }\end{array}$ & d 410 & $\begin{array}{l}\text { Changing the basic } \\
\text { position of the body }\end{array}$ & e 340 & Personal caretakers \\
\hline & & d 415 & Maintain body position & e 355 & $\begin{array}{l}\text { Healthcare } \\
\text { professionals }\end{array}$ \\
\hline & & d 430 & $\begin{array}{l}\text { Lifting and transporting } \\
\text { objects }\end{array}$ & e 360 & Other professionals \\
\hline & & d 440 & $\begin{array}{l}\text { Use fine hand } \\
\text { movements }\end{array}$ & e 430 & $\begin{array}{l}\text { Attitude of authority } \\
\text { figures }\end{array}$ \\
\hline & & d 445 & $\begin{array}{l}\text { Use of hand and arm } \\
\text { movements }\end{array}$ & e 450 & $\begin{array}{l}\text { Individual attitudes of } \\
\text { health professionals }\end{array}$ \\
\hline & & d 450 & Walking & e 460 & Social attitudes \\
\hline & & d 455 & Moving & e 465 & $\begin{array}{l}\text { Practical norms and } \\
\text { ideologies }\end{array}$ \\
\hline & & d 465 & Move using equipment & e 525 & $\begin{array}{l}\text { Housing services, } \\
\text { systems and policies }\end{array}$ \\
\hline & & d 470 & Transportation & e 535 & $\begin{array}{l}\text { Communication } \\
\text { services and policies }\end{array}$ \\
\hline & & d 475 & Conducting of vehicles & e 540 & $\begin{array}{c}\text { Transport services and } \\
\text { policies }\end{array}$ \\
\hline & & d 530 & $\begin{array}{l}\text { Care towards the } \\
\text { excretion process }\end{array}$ & e 550 & $\begin{array}{c}\text { Legal services, systems } \\
\text { and policies }\end{array}$ \\
\hline
\end{tabular}


Table 1. Categories of the core set of the International Classification of Functioning, Disability and Health for professional rehabilitation according to Finger et al. Continuation

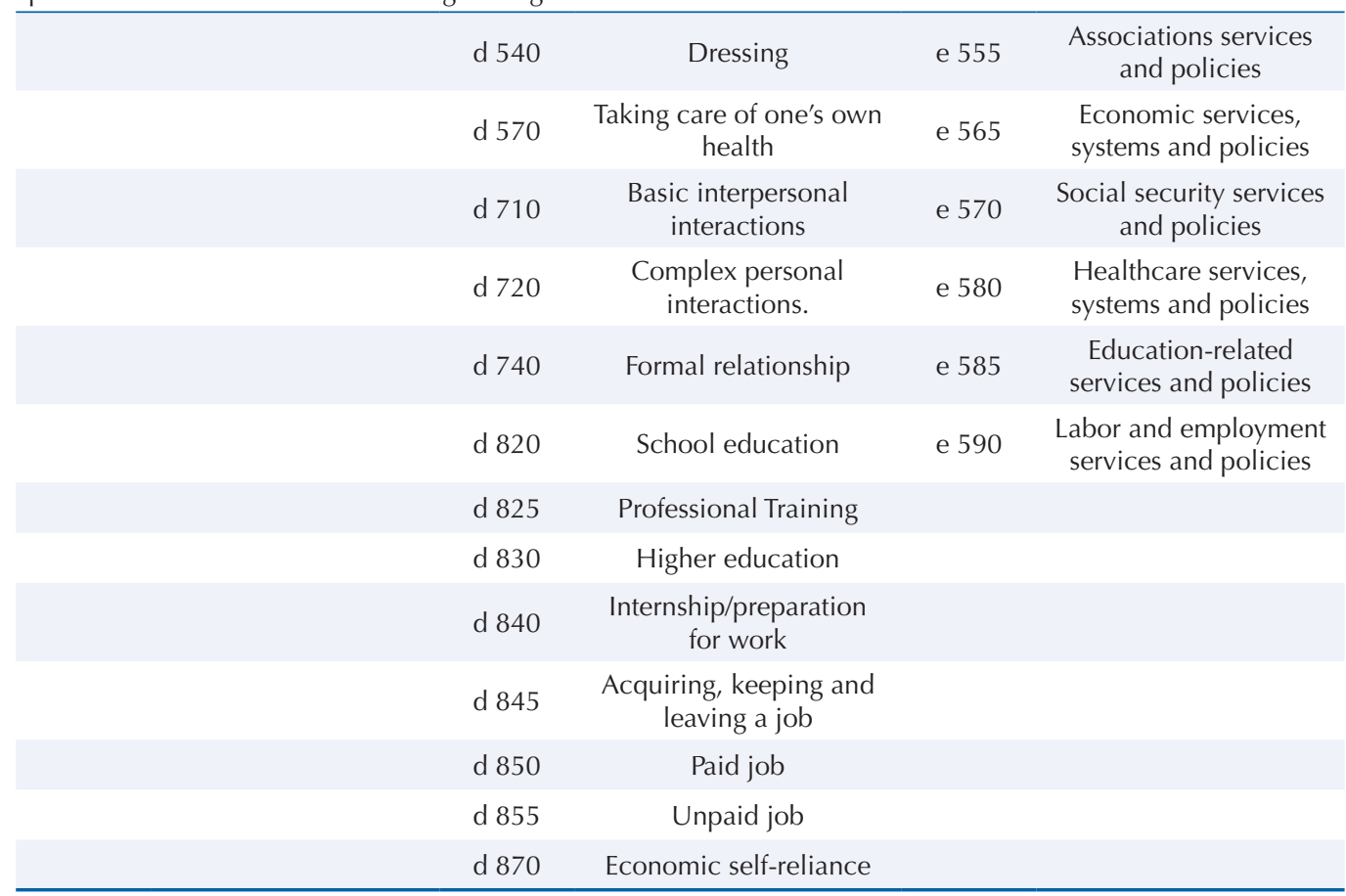

It is important to note that ICF and its core sets are merely classification instruments and in order for them to be accessed in a legitimate way with its findings being subject to comparison by peers, standardized methods are required to evaluate the functioning of different individuals, preferably compatible with the use of the classification ${ }^{14-15}$. In order to contribute to the operationalization of ICF, essential for the advancement of public PR policies in Brazil, this study aimed to review the instruments of functional assessment and health status that are used in the literature regarding functioning and health status of Brazilian workers in general and to verify the compatibility of their items with the categories of the core set for professional rehabilitation.

\section{METHODS}

A literature review was conducted in the PubMed, Scopus, Web of Science, Lilacs and SciELO databases, from January to July 2018, with the objective of identifying instruments for assessing the functioning and health status applied to populations of Brazilian workers of any category. The literature search included publications from January 2007 to December 2017.

The following descriptors were considered: "capacity evaluation, work," OR "disability evaluation, work," AND “functional assessment," OR “questionnaire.” The same descriptors were used for searching in Portuguese.

After the identification of the articles, the instruments used in the studies for the evaluation of workers were selected, and their contents were searched in full. Then, we selected those in which most items could respond to the categories of the core set of ICF for PR, including, preferably, those with items related to the evaluation of changes in body functions, limitation of activities and environmental issues, as proposed by the classification. From this, the analysis of the items of each instrument selected was made and the possibility of accessing the categories of the core set of ICF for PR was verified.

The compatibility of each item with the core set of the instruments identified in the literature, was independently verified by two evaluators, health professionals familiar with the use of 
ICF, as recommended in the literature ${ }^{15}$. For this analysis, it was considered what each item contemplated and thus established the connection with the core set through the detailed description and definitions of each category offered by ICF.

To verify the agreement between the evaluators in the selection of the categories used by the items of each instrument, Cohen's kappa coefficients were calculated, classified by the cutoff points proposed by Landis and $\mathrm{Koch}^{16}$ : below 0 (poor); 0 to 0.20 (weak); 0.21 to 0.40 (reasonable); 0.41 to 0.60 (moderate); 0.61 to 0.80 (substantial); and 0.81 to 1.00 (almost perfect).

After the analysis of the agreement, the non-concordant items were studied among the evaluators in search of consensus for either the removal or the inclusion of the item as compatible with the core set.

\section{RESULTS}

We found 13 assessment instruments used in research on functioning or health status of Brazilian workers in the period studied. Through the recovery of their contents, it was found that all were validated specifically for Brazil to evaluate aspects related to functioning or health status.

Between the thirteen reviewed instruments, five were created specifically for the evaluation of disabilities and work-related aspects, including: the Work Ability Index (WAI), the Cultural and Psychosocial Influences on Disability questionnaire (CUPID), the Work Disability Diagnosis Interview (WoDDI), the Obstacles to Return-to-Work Questionnaire (ORTWQ) and the Work Role Functioning Questionnaire (WRFQ). The others were instruments used by the researchers, on groups of workers, but created for specific evaluation of some anatomical regions or to verify quality of life in general without taking into account the nature and working conditions that may be associated with symptoms. The instruments analyzed and the number of categories of the core set for PR that could be accessed by each of them are presented in Table 2.

Among these instruments, four were developed based on ICF categories, which allows for a greater connection with said index: the World Health Organization Disability Assessment Schedule II (WHODAS), the Nottingham Health Profile (NHP), the World Health Organization Quality of Life questionnaire (WHOQOL) and the ORTWQ. The WHODAS showed substantial agreement between the evaluators in the link with the core set, and the others almost perfect agreement, as shown in Table 3. The other eight instruments reviewed were not created in order to be used with ICF, but the agreement between the items chosen by the evaluators as compatible with the categories of the core set was substantial or almost perfect for most and moderate for the CUPID (Table 3).

The analysis of the compatibility of the selected instrument items with the core set for PR highlighted the variability in the focus of each instrument when addressing functioning issues of the individual when the objective is occupational capacity. The proportion of categories in the core set accessed by the items of each questionnaire according to the components of ICF is presented in Graph 1 and the emphasis given to the evaluation of body functions and limitation of activities and participation is noted. Specific instruments for evaluating work-related aspects (WAI, CUPID, WoDDI, WRFQ and ORTWQ), including functioning limitations, were able to access, when analyzed together, 36 categories of the core set for professional rehabilitation (11 categories b, 15 categories d and 10 categories e).

WAI aims to highlight how well a worker is or will be in the near future and how well he is able to perform his work according to his demands, his health status and his physical and mental abilities. It includes aspects such as current capacity for work, capacity in relation to work requirements, number of diagnosed diseases, estimated loss of work ability and 
Table 2. Functional assessment and health status instruments selected for compatibility analysis with the core set of the International Classification of Functioning, Disability and Health for professional rehabilitation and number of categories of the core set that could be accessed in each domain.

\begin{tabular}{|c|c|c|c|c|c|}
\hline \multirow[b]{2}{*}{ Instrument } & \multirow{2}{*}{$\begin{array}{l}\text { Author, year and } \\
\text { place of study }\end{array}$} & \multirow[b]{2}{*}{ Sample of workers } & \multicolumn{3}{|c|}{ Number of categories accessed } \\
\hline & & & $\begin{array}{l}\text { Body functions } \\
\text { Total: } 17\end{array}$ & $\begin{array}{l}\text { Activity and participation } \\
\text { Total: } 40\end{array}$ & $\begin{array}{c}\text { Environmental factors } \\
\text { Total: } 33\end{array}$ \\
\hline WAI & $\begin{array}{l}\text { Walsh et al., } 2008 . \\
\text { São Carlos, SP. }\end{array}$ & $\begin{array}{l}134 \text { workers of a multinational } \\
\text { company }\end{array}$ & 3 & 9 & 0 \\
\hline CUPID & $\begin{array}{l}\text { Carugno et al., } 2012 . \\
\text { São Paulo, SP. }\end{array}$ & 751 nurses from public hospitals & 3 & 7 & 1 \\
\hline WoDDI & $\begin{array}{l}\text { Mininel et al., } 2012 . \\
\text { São Paulo, SP. }\end{array}$ & $\begin{array}{l}30 \text { workers of the University Hospital } \\
\text { of USP }\end{array}$ & 6 & 6 & 5 \\
\hline WRFQ & $\begin{array}{l}\text { Galash and Costa, } \\
\text { 2007. Campinas, SP. }\end{array}$ & 105 workers (formal or informal) & 1 & 14 & 0 \\
\hline ORTWQ & $\begin{array}{l}\text { Milani et al., } 2016 . \\
\text { Campinas, SP. }\end{array}$ & 301 miscellaneous workers & 3 & 2 & 4 \\
\hline WHODAS & $\begin{array}{l}\text { Valério et al., } 2016 . \\
\text { Uberaba, MG. }\end{array}$ & 94 active workers (formal or informal) & 2 & 13 & 1 \\
\hline NHP & $\begin{array}{l}\text { Bartilotti et al., } 2009 . \\
\text { Florianópolis, SC. }\end{array}$ & $\begin{array}{c}425 \text { workers assisted at CEREST in } \\
\text { Santa Catarina }\end{array}$ & 5 & 7 & 1 \\
\hline FIM & $\begin{array}{l}\text { Bartilotti et al., } 2009 . \\
\text { Florianópolis, SC. }\end{array}$ & $\begin{array}{c}425 \text { workers assisted at CEREST in } \\
\text { Santa Catarina }\end{array}$ & 1 & 8 & 0 \\
\hline DASH. & $\begin{array}{l}\text { Camargo et al., } 2007 . \\
\text { São Carlos, SP. }\end{array}$ & 27 industrial workers & 4 & 5 & 0 \\
\hline ODI & $\begin{array}{l}\text { Walsh et al., } 2008 . \\
\text { São Carlos, SP. }\end{array}$ & $\begin{array}{l}134 \text { workers of a multinational } \\
\text { company }\end{array}$ & 2 & 6 & 0 \\
\hline $\mathrm{RMQ}$ & $\begin{array}{l}\text { Sardá Jr et al., } 2009 . \\
\text { Florianópolis, SC. }\end{array}$ & 234 refrigerator workers & 3 & 7 & 01 \\
\hline SF-36 & $\begin{array}{l}\text { Sena et al., } 2013 . \\
\text { Lagarto, SE. }\end{array}$ & 351 rural workers & 3 & 10 & 0 \\
\hline WHOQOL-BREF & $\begin{array}{l}\text { Ferreira et al., } 2017 . \\
\quad \text { São Paulo, SP. }\end{array}$ & 50 butchers & 4 & 6 & 11 \\
\hline
\end{tabular}

WAl; Work Ability Index; CUPID: Cultural and Psychosocial Influences on Disability questionnaire; WoDDI: Work Disability Diagnosis Interview; WRFQ: Work Role Functioning Questionnaire; ORTWQ: Obstacles to Return-to-Work Questionnaire; WHODAS: World Health Organization Disability Assessment Schedule II; NHP: Nottingham Health Profile; FIM: Functional Independence Measure; DASH: Disabilities of the Arm, Shoulder and Hand questionnaire; ODI: Oswestry Low Back Pain Disability Questionnaire; RMQ: Roland-Morris Questionnaire; SF-36: Short Form (36) Health Survey; WHOQOL-BREF: short version of the World Health Organization Quality of Life questionnaire; USP: Universidade de São Paulo; CEREST: Centro de Referência em Saúde do Trabalhador (Reference Center in Occupational Health)

Table 3. Instruments analyzed and kappa values found in the analysis of agreement between the evaluators.

\begin{tabular}{|c|c|}
\hline Instrument & Kappa value \\
\hline WRFQ & 0.91 \\
\hline NHP & 0.87 \\
\hline ODI & 0.86 \\
\hline ORTWQ & 0.83 \\
\hline DASH. & 0.82 \\
\hline WHOQOL-BREF & 0.81 \\
\hline SF-36 & 0.78 \\
\hline WHODAS & 0.74 \\
\hline RMQ & 0.73 \\
\hline FIM & 0.72 \\
\hline WAI & 0.67 \\
\hline WoDDI & 0.61 \\
\hline CUPID & 0.49 \\
\hline
\end{tabular}

WRFQ: Work Role Functioning Questionnaire; NHP: Nottingham Health Profile; ODI: Oswestry Low Back Pain Disability Questionnaire; ORTWQ: Obstacles to Return-to-Work Questionnaire; DASH: Disabilities of the Arm, Shoulder and Hand questionnaire; WHOQOL-BREF: short version of the World Health Organization Quality of Life questionnaire; SF-36: Short Form (36) Health Survey; WHODAS: World Health Organization Disability Assessment Schedule II; RMQ: Roland-Morris Questionnaire; FIM: Functional Independence Measure; WAI: Work Ability Index; WoDDI: Work Disability Diagnosis Interview; CUPID: Cultural and Psychosocial Influences on Disability questionnaire Note: Classification according to Landis and $\operatorname{Koch}^{16}$ : poor $(<0)$, weak $(0$ to 0.20$)$, reasonable $(0.21$ to 0.40$)$, moderate (0.41 to 0.60$)$, substantial $(0.61$ to 0.80$)$, almost perfect $(0.81$ to 1$)$. 
absence due to diseases, which is prognosis of work ability two years in the future as well as mental resources. From its items it was possible to connect it with 12 categories of the core set in question.

CUPID aims to associate the musculoskeletal symptoms of workers with their activities, psychosocial aspects and other disabilities. Validated for Brazil as an International Survey on Physical, Cultural and Psychosocial Influences on Musculoskeletal Symptoms and Associated Disabilities, it verifies physical activities at work, psychosocial aspects, musculoskeletal symptoms in various anatomical sites associated with disability for common daily tasks, mental health and tendency to worry about symptoms, as well as beliefs about the nature and severity of work-related diseases. This instrument allowed for a connection with 11 categories.

WoDDI seeks to detect the most important predictive factors for work-related disabilities and to identify one or more causes of prolonged absenteeism. Validated for Brazil as an Instrument for Identifying the Situation of Disability at Work, it analyzes the history of current illness, pain, previous and current health condition, physical examination, life habits, socio-family history, financial situation, work environment, worker perceptions and analysis of results and recommendations. These items were compatible with 17 categories of the core set.

WRFQ is validated for the Portuguese language as a Work Performance Assessment Questionnaire and assesses whether the worker's functional capacity is altered due to health problems. It analyzes the work-related, physical, mental, social and productionrelated demands. It was connected to 15 categories.

The last instrument used for evaluation of workers, ORTWQ, was created under the influence of ICF and evaluates barriers related to return to work. Validated for Brazil as Obstacles for the Return to Work, it contains 55 items divided into nine domains: difficulty of return, physical load and self-perception of harmfulness in work, social support, concern due to absence, satisfaction, family support or situation, and self-perceived prognosis of return to work. Although extensive, the analysis of these items allowed for a connection with only nine categories of the core set.

The other reviewed instruments were adapted to propose different problems for the workers and, when linked to the core set for professional rehabilitation, also presented variability within the categories answered, with emphasis on body functions and limitation of activities. When used in conjunction, these instruments were able to access a total of 45 categories, with seven being related to body functions, 24 to activities and participation and 13 to environmental factors.

WHODAS was created by the World Health Organization to provide direct correlation with ICF and serve as a standardized method for measuring health and disabilities in a cross-cultural way. It contains 36 items and provides level of functioning in six domains: cognition, mobility, self-care, interpersonal relationships, life activities and participation. From its items it was possible to connect it with 16 categories of the core set in question.

NHP is a generic instrument with 38 items that refer to the following aspects: energy level, pain, emotional reactions, sleep, social interaction and physical abilities. It aims to evaluate the quality of life in patients with chronic diseases. The analysis of its items showed compatibility with 13 categories.

The Functional Independence Measure (FIM), validated for the Portuguese language, was elaborated based on the categories of the test version of ICF called International Classification of Impairments, Disabilities, and Handicaps (ICIDH). Validated for a wide category of people in Brazil, it measures the level of disability of the individual and how much assistance is required to perform his or her activities. It has 18 items distributed in 
Table 4. List of the categories of the core set for professional rehabilitation accessed by the ten assessment instruments selected as the minimum to respond to the core set.

\begin{tabular}{|c|c|}
\hline Categories* & Instruments \\
\hline b 126: temperament functions & RMQ, DASH, WRFQ \\
\hline b 130: energy and impulse functions & WAI, ORTWQ, SF-36, WHOQOL-BREF \\
\hline b 134: sleep functions & WAI, WoDDI, RMQ, DASH, WHOQOL-BREF \\
\hline b 140: attention-related functions & WAI \\
\hline b 144: memory functions & WHODAS \\
\hline b 152: emotional functions & CUPID, WAI, ORTWQ, WoDDI, SF-36, WHODAS, WHOQOL-BREF \\
\hline b 210: vision-related functions & WAI \\
\hline b 230: hearing-related functions & WAI \\
\hline b 235: vestibular functions & CUPID \\
\hline b 280: feeling of pain & CUPID, WAI, ORTWQ, WoDDI, RMQ, DASH, SF-36, WHOQOL-BREF \\
\hline b 455: tolerance to physical exercise & WAI, WoDDI \\
\hline b 730: muscle strength functions & WoDDI, DASH \\
\hline b 810: skin protection functions & WAI, WoDDI \\
\hline d 160: focus & WHODAS, WHOQOL-BREF, WRFQ \\
\hline d 163: thinking & WRFQ \\
\hline d 166: reading & WRFQ \\
\hline d 170: writing & CUPID, DASH \\
\hline d 175: problem-solving & WAI, WHODAS \\
\hline d 177: decision-making & WAI \\
\hline d 210: accomplishing a single task & ORTWQ, WHODAS, WRFQ \\
\hline d 220: performing multiple tasks & $\mathrm{RMQ}$ \\
\hline $\begin{array}{l}\text { d 230: accomplishment of daily } \\
\text { routine }\end{array}$ & CUPID, RMQ, SF-36, WHODAS, WHOQOL-BREF \\
\hline $\begin{array}{l}\text { d 310: communicating (verbal } \\
\text { messages) }\end{array}$ & WHODAS, WRFQ \\
\hline d 350: conversation & WHODAS \\
\hline d 360: use of communication devices & WRFQ \\
\hline $\begin{array}{l}\text { d } 410 \text { : changing the basic position of } \\
\text { the body }\end{array}$ & CUPID, RMQ, SF-36, WHODAS, WRFQ \\
\hline d 415: maintain body position & RMQ, WHODAS, WRFQ \\
\hline d 430: lifting and transporting objects & WoDDI, DASH, SF-36, WRFQ \\
\hline d 440: use fine hand movements & DASH, CUPID, WRFQ \\
\hline d 445: use of the hand and arm & DASH, CUPID, ORTWQ, SF-36, WRFQ \\
\hline d 450: walking & CUPID, WoDDI, RMQ, SF-36, WHODAS, WHOQOL-BREF, WRFQ \\
\hline d 455: moving & SF-36 \\
\hline d 465: moving with equipment & WoDDI, RMQ \\
\hline d 470: use of transportation & DASH \\
\hline $\begin{array}{l}\text { d 530: care towards the excretion } \\
\text { process }\end{array}$ & FIM \\
\hline d 540: dressing & CUPID, RMQ, DASH, SF-36, WHODAS \\
\hline d 570: taking care of one's own health & WHODAS \\
\hline d 710: basic interpersonal interactions & SF-36, WHODAS, WHOQOL-BREF \\
\hline d 740: formal relationship & WoDDI, WRFQ \\
\hline $\begin{array}{l}\text { d } 845 \text { : acquiring, keeping and leaving } \\
\text { a job }\end{array}$ & SF-36 \\
\hline d 850: paid work & WAI, WoDDI, SF-36, WHODAS, WHOQOL-BREF, WRFQ \\
\hline d 870: economic self-reliance & WoDDI, WHOQOL-BREF \\
\hline e 1101: medication & WoDDI \\
\hline
\end{tabular}

Continue 
Table 4. List of the categories of the core set for professional rehabilitation accessed by the ten assessment instruments selected as the minimum to respond to the core set. Continuation

\begin{tabular}{|c|c|}
\hline e 120: mobility products & $\mathrm{RMQ}$ \\
\hline e 150: architecture (public buildings) & WHODAS \\
\hline e 225: climate & WoDDI, WHOQOL-BREF \\
\hline e 240: light & WHOQOL-BREF \\
\hline e 250: sound & WoDDI, WHOQOL-BREF \\
\hline e 260: air quality & WoDDI, WHOQOL-BREF \\
\hline e 310: immediate family & ORTWQ, WHOQOL-BREF \\
\hline e 320: friends & ORTWQ, WHOQOL-BREF \\
\hline e 325: acquaintances & ORTWQ, WoDDI, WHOQOL-BREF \\
\hline e 330: authority figures & CUPID \\
\hline e 355: healthcare professionals & WHOQOL-BREF \\
\hline e 430: attitude of authority figures & ORTWQ \\
\hline e 525: housing-related services & WHOQOL-BREF \\
\hline e 525: transportation-related services & WHOQOL-BREF \\
\hline e 580: health services & WoDDI, WHOQOL-BREF \\
\hline
\end{tabular}

WRFQ: Work Role Functioning Questionnaire; NHP: Nottingham Health Profile; ODI: Oswestry Low Back Pain Disability Questionnaire; ORTWQ: Obstacles to Return-to-Work Questionnaire; DASH: Disabilities of the Arm, Shoulder and Hand questionnaire; WHOQOL-BREF: short version of the World Health Organization Quality of Life questionnaire; SF-36: Short Form (36) Health Survey; WHODAS: World Health Organization Disability Assessment Schedule II; RMQ: Roland-Morris Questionnaire; FIM: Functional Independence Measure; WAI: Work Ability Index; WoDDI: Work Disability Diagnosis Interview; CUPID: Cultural and Psychosocial Influences on Disability questionnaire

Note: 32 categories of the core set, described in Table 1, were not identified in any instrument, four of which were body-related functions (b117, b160, b164, b740), 11 activities and participation (d155, d172, d240, d315, d475, d720, d820, d825, d830, d840, d855) and 17 environmental factors (e115, e125, e130, e135, e155, e340, e360, e450, e460, e465, e535, e550, e565, e555, e570, e585, e590).

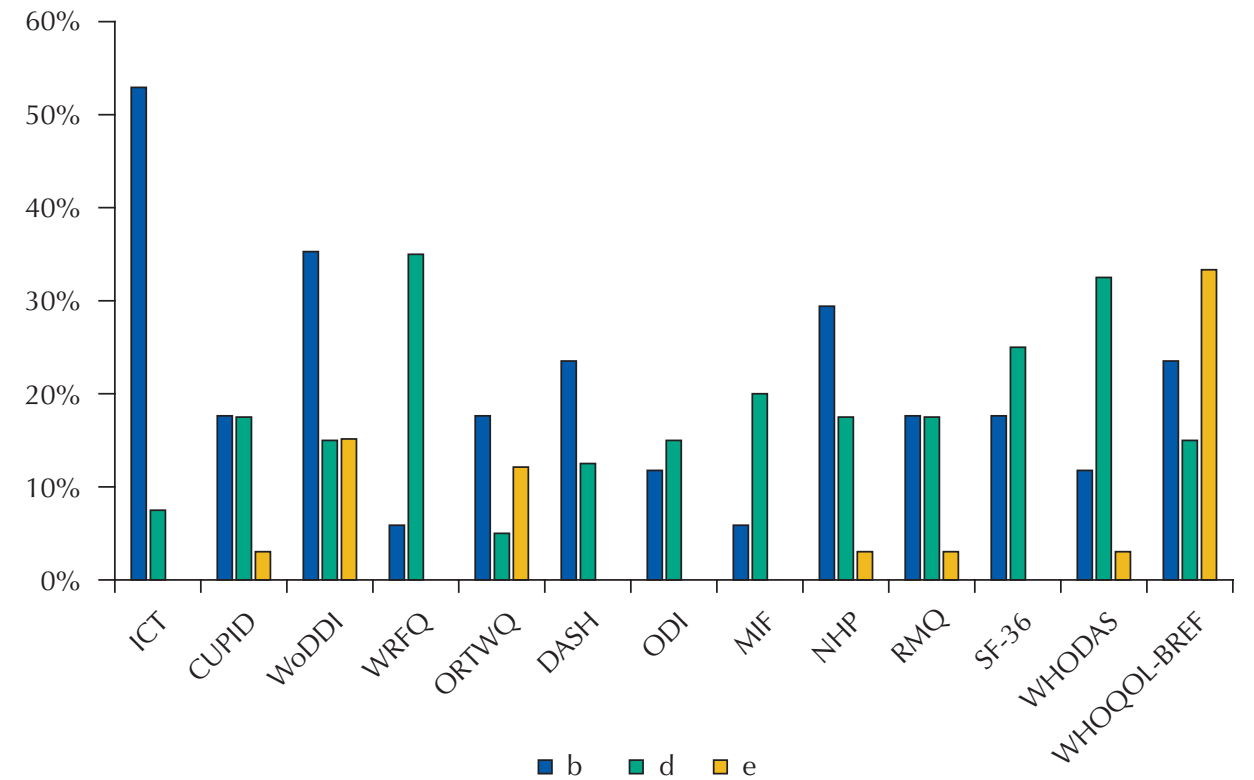

WAI; Work Ability Index; CUPID: Cultural and Psychosocial Influences on Disability questionnaire; WoDDI: Work Disability Diagnosis Interview; WRFQ: Work Role Functioning Questionnaire; ORTWQ: Obstacles to Return-to-Work Questionnaire; DASH: Disabilities of the Arm, Shoulder and Hand questionnaire; ODI: Oswestry Low Back Pain Disability Questionnaire; FIM: Functional Independence Measure; NHP: Nottingham Health Profile; RMQ: Roland-Morris Questionnaire; SF-36: Short Form (36) Health Survey; WHODAS: World Health Organization Disability Assessment Schedule II; WHOQOL-BREF: short version of the World Health Organization Quality of Life questionnaire.

Graph 1. Proportion of categories filled by the instruments analyzed in each domain of the core set for professional rehabilitation. 
the following domains: self-care, sphincter control, mobility, locomotion, communication and social interaction. It was compatible with 18 categories of the core set.

Another instrument used in the evaluation of functioning in workers is the Disabilities of the Arm, Shoulder and Hand questionnaire (DASH), created to assess upper limb dysfunction and physical symptoms in any group of people. It includes 30 items related to pain, weakness, stiffness, tingling, daily activities, household chores, shopping, recreational activities, self-care, dressing, eating, sexual activities, sleeping, family care, work, socialization, and self-image. Regarding the core set, the DASH allowed for the access of nine categories.

The Oswestry Low Back Pain Disability Questionnaire (ODI) and the Roland-Morris Questionnaire (RMQ) are also used for functional capacity assessment. Both validated for Brazil in several population types, they evaluate the effect of lower back pain on functionality. They were connected to 8 and 11 categories of the core set, respectively.

The last two reviewed instruments evaluated the quality of life of individuals, considering functional aspects. The Short Form (36) Health Survey (SF-36) assesses the quality of life of individuals and includes questions related to functioning. It is a generic form, and addresses the following aspects: functional capacity, physical aspects, pain, general health status, vitality, social aspects, emotional aspects, mental health and comparative health assessment. It allowed for connections with 13 categories.

WHOQOL-BREF also assesses quality of life. It is a reduced version of WHOQOL, proposed by the WHO to be used in a cross-cultural way, composed of 26 items distributed in four domains: physical, psychological, social relations and the environment. It allowed for the connection to 21 categories.

According to this present study, it would be necessary to use a combination of instruments to evaluate all aspects considered relevant pointed out in the categories of core set for professional rehabilitation. Completing the maximum categories of the core set using the least possible instruments would require the use of 10 of the 13 reviewed in this study and it would be possible to access 58 of the 90 proposed categories (Table 4). Among them, 13 (76\%) would refer to the component of body functions, $28(72.5 \%)$ activities and participation and 16 (49\%) environmental factors.

Most instruments prioritize the evaluation of changes in body functions and the identification of limitation of activities that may interfere with work, as they were analyzed to work with the core set for professional rehabilitation. Environmental factors are considered by six instruments; therefore, environmental interference as a facilitator or barrier is poorly addressed by most of the instruments raised.

\section{DISCUSSION}

This study aimed to analyze instruments for the assessment of functioning to access the core set of ICF for PR, aiming to improve the understanding functioning measures in this area and elucidate possible ways of using the classification. This core set was chosen because it is the only one in the literature created to guide the classification of the functioning of workers in rehabilitation, through ICF. To use it, it is important to apply validated instruments that reliably measure functioning, generating results that can be compared in research ${ }^{2}$.

The review conducted during the research showed the multiplicity of instruments used in the approach of functional issues related to work. Those who could reach ICF domains were eligible, accounting for the maximum number of categories in the core set studied. Thus, five specific instruments and eight generic instruments were selected that evaluated functioning published in the proposed period. 
The wide variety of instruments available, with different theoretical bases, leads to the need for decisions on the part of researchers and makes it difficult to compare and standardize the results ${ }^{17}$. One way to compensate for this gap is to link different assessment instruments to a single conceptual model that favors a common framework for comparing measures ${ }^{18-20}$.

ICF is a WHO-endorsed theoretical conceptual basis designed to classify functioning and disability of individuals and promote a unique and comprehensive language about the health status of different populations ${ }^{21,22}$. It is linked to evaluation instruments, and as such it allows the translation of these measures into the same language (that is, ICF codes), facilitating the content analysis of its items and the understanding and comparison of the results ${ }^{23}$.

Analyzed based on the core set for PR, it was possible to notice that the instruments gather common items but differ in the approach of the domains considered by ICF. About $38 \%$ of the categories in the core set could be accessed by more than one of the 13 instruments. In relation to the domains, the components related to problems in body functions, limitation of activities and participation were the most represented, evidencing the concern to verify physical illness and the experience of workers in the various activities involved.

A total of 32 of the 90 categories of the core set could not be accessed through the items of the instruments found. The body functions component had four unanswered categories (23\%), the one related to activities and participation had four unanswered categories (27.5\%) and the least represented component was the one related to environmental factors, with 17 unanswered categories (51.5\%).

Other authors also verified this lower representativeness of items related to the categories of environmental factors of ICF in correlations with other instruments ${ }^{17,19,24-26}$. As such, this fact disfavors the approach given to functioning, since it ignores an important influencing component in the functioning of individuals, highly considered by the biopsychosocial model that supported $\mathrm{ICF}^{23,27}$.

In PR, environmental factors (be they physical, social and attitudinal) should be emphasized, since they are important influencing factors in work participation, interacting with body conditions (functions and body structures) and determining the level and extent of its functioning ${ }^{1,28}$. The main objective of this process is the recovery of labor capacity in an effective and lasting manner, which is closely associated with workplace conditions ${ }^{3}$.

To remain active and productive, the worker needs to be in a favorable environment; which must include facilitators of functioning, from adequate ergonomic conditions to organizational changes that generate well-being, increased self-esteem, autonomy at work and healthy relationships ${ }^{1,29}$. Even highly disabled individuals can have their possible participation recovered if the modification of the environment is among the priorities of $\mathrm{PR}^{1,3}$. This process occurs with the analysis of environmental factors that must be carefully inserted in the evaluation and monitoring of each worker ${ }^{3}$.

The kappa coefficient, used to verify the agreement between the evaluators who analyzed the correspondence of the items of the instruments with the categories of the core set, ranged from moderate agreement $(\mathrm{k}=0.49)$ for an instrument to almost perfect $(\mathrm{k}>0.80)$ for seven instruments (Table 3). This result indicates that, although the instruments do not offer a direct link with ICF, the evaluators had a common understanding in choosing most of the categories accessed by each item.

Similar results have been found in other studies in the connection of ICF with different tools, and the authors point out that disagreement between the evaluators may be due to ICF presenting more specific categories in some areas than in other ${ }^{19,22,27}$. In addition, the interpretation of a given concept in an item of an instrument may differ among evaluators, in such a way that distinct categories of the core set could be selected; this justifies the need for consensus in the final choice of categories accessed by the questionnaires ${ }^{30}$. The link of 
assessment instruments with ICF allows a standardized analysis of its contents, favoring the choice of the most appropriate instrument for use in clinical practice ${ }^{25,30}$.

According to this study, the evaluation of all aspects considered relevant in the worker's functionality, suggested in the core set for professional rehabilitation, would require the combination of several instruments and the search for more forms of evaluation to include the missing items, since not all categories were contemplated. This is an acceptable result, since the core sets are instruments created by a consensus-based methodology among experts who seek to gather categories of ICF aimed at specific groups of the population, based on knowledge and clinical experience in the area, without taking into account the assessment instruments available to access them ${ }^{31-33}$.

For ICF and its core sets to be used more conveniently and uniformly, it is recommended to create measurement instruments attuned to the classification ${ }^{34}$. For this, the authors of this core set created the Work Rehabilitation Questionnaire (WORQ) ${ }^{34}$, adapted for Brazil as a Rehabilitation Questionnaire for Work, which can be used to evaluate several categories, providing a direct link with ICF.

This study is innovative when analyzing a considerable number of instruments that have been applied in the evaluation of the functioning of workers and verifying their approaches using as reference an ICF core set specific to this area of activity. The fact that not all instruments available for functional evaluation including physical or psychic aspects that can be used with workers were analyzed does not compromise the study result, since its objective was to illustrate the operationalization of ICF through this specific core set, prioritizing instruments that could respond to the largest possible number of categories.

In this sense, it was observed that it was not possible to establish linkage of items with all categories of the core set when instruments created without the purpose of using the classification are used. Further studies are needed to verify the degree of compatibility between how each tool quantifies the magnitude of the evaluated commitment and the technique adopted by ICF through its qualifiers, a fact that can constitute another barrier for the classification of the functioning evaluated from these instruments.

In addition, the link to the same conceptual basis allowed the visualization of the common aspects among the instruments studied, as well as the differences in the way of approaching the functioning or health status of individuals.

It was clear that environmental factors are still highly disregarded by functioning evaluation models used in research with workers. This is negative when it aims to restore work capacity and reinsert the individual in his or her workplace, because environmental factors are determinant for the effectiveness of actions and maintenance of functioning. It is necessary to include the evaluation of the environment in the PR process, and this can be done with the use of ICF, taking as reference the environmental categories suggested by the core set studied.

\section{CONCLUSION}

The review of instruments for assessing the functioning and health status of workers and the subsequent link with the core set for professional rehabilitation performed by this study concluded that at least ten instruments would be necessary to evaluate $65 \%$ of the aspects considered relevant in the categories of the core set for professional rehabilitation. The component related to environmental factors in the core set was the one that presented the lowest possibility for answers through the items of the studied questionnaires, which indicates the minor emphasis given to these factors in disabilities. Associating multiple instruments to respond to a specific core set requires time and makes it difficult to use 
the classification. Evaluation instruments designed to allow direct association with ICF categories, and its qualifiers are essential to operationalize it.

\section{REFERENCES}

1. Escorpizo R, Soren B, Homa DB, Stucki G, eeditors. Handbook of vocational rehabilitation and disability evaluation: application and implementation of the ICF. New York: Springer; 2015.

2. Finger ME, Escorpizo R, Glässel A, Gmünder HP, Lückenkemper M, Chan C, et al. ICF Core Set for vocational rehabilitation: results of an international consensus conference. Disabil Rehabil. 2012;34(5):429-38. https://doi.org/10.3109/09638288.2011.608145

3. Martins AC. Using the International Classification of Functioning, Disability and Health (ICF) to address facilitators and barriers to participation at work. Work. 2015;50(4):585-93. https://doi.org/10.3233/WOR-141965

4. Organização Mundial da Saúde. Classificação Internacional de Funcionalidade, Incapacidade e Saúde- CIF. Trad. Centro Colaborador da Organização Mundial da Saúde para a Família de Classificações Internacionais. São Paulo: EDUSP; 2003.

5. Araújo ES, Buchalla CM. Using the ICF in work-related physiotherapy: a contribution to data collection about functioning. Acta Fisiatr. 2013;20(1):1-7.

6. Rauch A, Cieza A, Stucki G. How to apply the International Classification of Functioning, Disability and Health (ICF) for rehabilitation management in clinical practice. Eur J Phys Rehabil Med. 2008;44(3):329-42.

7. Escorpizo R, Finger ME, Glässel A, Gradinger F, Lückenkemper M, Cieza A. A systematic review of functioning in vocational rehabilitation using the International Classification of Functioning, Disability and Health. J Occup Rehabil. 2011;21(2):134-46. https://doi.org/10.1007/s10926-011-9290-8

8. Reneman MF, Beemster TT, Edelaar MJA, Velzen JM, Beneekom C, Escorpizo R. Towards an ICF- and IMMPACT-Based Pain Vocational Rehabilitation Core Set in the Netherlands. J Occup Rehabil. 2013;23(4):573-84. https://doi.org/10.1007/s10926-013-9423-3

9. Prodinger B, Tennant A, Stucki G. Standardized reporting of functioning information on ICF-based common metrics. Eur J Phys Rehabil Med. 2018;54(1):110-7. https://doi.org/10.23736/S1973-9087.17.04784-0

10. Ministério da Previdência Social (BR). Instituto Nacional de Seguridade Social. Manual técnico de procedimentos da área da reabilitação profissional. Brasília, DF; 2016.

11. Miranda CB. Aspectos do cenário atual da reabilitação profissional no Brasil: avanços e retrocessos. Cad Saude Publica. 2018;34(8):e00218717. https://doi.org/10.1590/0102-311x00218717

12. Maeno M, Vilela RAG. Reabilitação profissional no Brasil: elementos para a construção de uma política pública. Rev Bras Saude Ocup. 2010;35(121):87-99. https://doi.org/10.1590/S0303-76572010000100010

13. Momsen AH, Stapelfeldt CM, Rosbjerg R, Escorpizo R, Labriola M, Bjerrum M. International Classification of Functioning, Disability and Health in vocational rehabilitation: a scoping review of the state of the field. J Occup Rehabil. 2019;29(2):241-73. https://doi.org/10.1007/s10926-018-9788-4

14. Carvalho FN, Koifman RJ, Bergmann A. International Classification of Functioning, Disability, and Health in women with breast cancer: a proposal for measurement instruments. Cad Saude Publica. 2013;29(6):1083-93. https://doi.org/10.1590/S0102-311X2013000600005

15. Cieza A, Geyh S, Chatterji S, Kostanjsek N, Ustun B, Stucki G. ICF linking rules: an update based on lessons learned. J Rehabil Med. 2005;37(4):212-8. https://doi.org/10.1080/16501970510040263

16. Landis JR, Koch GG. The measurement of observer agreement for categorical data. Biometrics. 1977;33(1):159-74.

17. Laxe S, Tschiesner U, Zasler N, López-Blazquez R, Tormos JM, Bernabeu M. What domains of the International Classification of Functioning, Disability and Health are covered by the most commonly used measurement instruments in traumatic brain injury research? Clin Neurol Neurosurg. 2012;114(6):645-50. https://doi.org/10.1016/j.clineuro.2011.12.038 
18. Prodinger B, O'Connor RJ, Stucki G, Tennant A. Establishing score equivalence of the Functional Independence Measure motor scale and the Barthel Index, utilising the International Classification of Functioning, Disability and Health and Rasch measurement theory. J Rehabil Med. 2017;49(5):416-22. https://doi.org/10.2340/16501977-2225

19. Forget NJ, Higgins J. Comparison of generic patient-reported outcome measures used with upper extremity musculoskeletal disorders: linking process using the International Classification of Functioning, Disability, and Health (ICF). J Rehabil Med. 2014;46(4):327-34. https://doi.org/10.2340/16501977-1784

20. Rat AC, Guillemin F, Pouchot J. Mapping the osteoarthritis knee and hip quality of life (OAKHQOL) instrument to the international classification of functioning, disability and health and comparison to five health status instruments used in osteoarthritis. Rheumatology. 2008;47(11):1719-25. https://doi.org/10.1093/rheumatology/ken352

21. Azzopardi RV, Vermeiren S, Gorus E, Habbig AK, Petrovic M, Van Den Noortgate N, et al. Linking frailty instruments to the International Classification of Functioning, Disability, and Health: a systematic review. J Am Med Dir Assoc. 2016;17(11):1066.e1-1066.e11. https://doi.org/10.1016/j.jamda.2016.07.023

22. Prodinger B, Cieza A, Oberhauser C, Bickenbach J, Üstün TB, Chatterji S, et al. Toward the International Classification of Functioning, Disability and Health (ICF) rehabilitation set: a minimal generic set of domains for rehabilitation as a health strategy. Arch Phys Med Rehabil. 2016;97(6):875-84. https://doi.org/10.1016/j.apmr.2015.12.030

23. Marques A, Martins A, Jácome C, Figueiredo D. Linking the EASY-Care Standard to the International Classification of Functioning, Disability and Health. Disabil Rehabil. 2014;36(7):593-9. https://doi.org/10.3109/09638288.2013.804598

24. Wong AWK, Lau SCL, Cella D, Lai JS, Xie G, Chen L, et al. Linking of the Quality of Life In Neurological Disorders (Neuro-QoL) to the International Classification of Functioning, Disability and Health. Qual Life Res. 2017;26(9):2435-48. https://doi.org/10.1007/s11136-017-1590-9

25. Bartoszek G, Fischer U, Müller M, Strobl R, Grill E, Nadolny S, et al. Outcome measures in older persons with acquired joint contractures: a systematic review and content analysis using the ICF (International Classification of Functioning, Disability and Health) as a reference. BMC Geriatr. 2016;16:40. https://doi.org/10.1186/s12877-016-0213-6

26. Fréz AR, Vignola BAP, Kaziyama HHS, Spezzano LC, Filippo TRM, Imamura M, et al. The relationship between the Functional Independence Measure and the International Classification of Functioning, Disability, and Health Core Set for stroke. Acta Fisiatr. 2013;20(1):24-8. https://doi.org/10.5935/0104-7795.20130005

27. Campos TF, Rodrigues CA, Farias IMA, Ribeiro TS, Melo LP. Comparison of instruments for sleep, cognition and function evaluation in stroke patients according to the International Classification of Functioning, Disability and Health (ICF). Braz J Phys Ther. 2012;16(1):23-9. http://doi.org/10.1590/S1413-35552012000100005

28. Escorpizo R, Glässel A. The role of the ICF in physical therapy and vocational rehabilitation: contributing to developments in occupational health. Phys Ther Rev. 2013;18(5):368-72. https://doi.org/10.1179/1743288X13Y.0000000086

29. Finger ME, Selb M, De Bie R, Escorpizo R. Using the International Classification of Functioning, Disability and Health in physiotherapy in multidisciplinary vocational rehabilitation: a case study of low back pain. Physiother Res Int J. 2014;20(4):231-41. https://doi.org/10.1002/pri.1587

30. Eckert KG, Lange MA. Comparison of physical activity questionnaires for the elderly with the International Classification of Functioning, Disability and Health (ICF): an analysis of content. BMC Public Health. 2015;15:249-261. https://doi.org/10.1186/s12889-015-1562-3

31. Stucki G, Rauch A, Cieza A, Bickenbach JE. ICF Core Sets: manual for clinical practice. Göttingen (DEU): Hogrefe; 2012.

32. Aiachini B, Cremascoli S, Escorpizo R, Pistarini C. Validation of the ICF Core Set for Vocational Rehabilitation from the perspective of patients with spinal cord injury using focus groups. Disabil Rehabil. 2016;38(4):337-45. https://doi.org/10.3109/09638288.2015.1041611

33. Riberto M. Core sets da Classificação Internacional de Funcionalidade, Incapacidade e Saúde. Rev Bras Enferm. 2011;64(5):938-46. https://doi.org/10.1590/S0034-71672011000500021 
34. Finger ME, Escorpizo R, Bostan C, De Bie R. Work Rehabilitation Questionnaire (WORQ): development and preliminary psychometric evidence of an ICF-based questionnaire for vocational rehabilitation. J Occup Rehabil. 2014;24(3):498-510. https://doi.org/10.1007/s10926-013-9485-2

Authors' contribution: Study design:JSL, GTRM, RJK. Data collection, analysis and interpretation: JSL, GTRM, RJK. Writing of the manuscript and approval of the final version: JSL, GTRM, RJK, AB. Public responsibility for the content of the article: JSL, GTRM, RJK, AB.

Conflict of Interest: The authors declare no conflict of interest. 